\title{
Early removal of chest drains in patients following off-pump coronary artery bypass graft (OPCAB) is not inferior to standard care - study in the Enhanced Recovery After Surgery (ERAS) group
}

\author{
Slawomir Zurek ${ }^{1,2}$, Arkadiusz Kurowicki ${ }^{1}$, Michal Borys $^{3}$, Artur Iwasieczko', Bogumila Woloszczuk-Gebicka ${ }^{2}$, \\ Miroslaw Czuczwar ${ }^{3}$, Kazimierz Widenka ${ }^{1,2}$ \\ ${ }^{1}$ Clinical Department of Cardiac Surgery, District Hospital No. 2, Rzeszow, Poland \\ ${ }^{2}$ Medical College, University of Rzeszow, Rzeszow, Poland \\ ${ }^{3}$ Second Department of Anesthesia and Intensive Care, Medical University of Lublin, Lublin, Poland \\ Kardiochirurgia i Torakochirurgia Polska 2021; 18 (2): 71-74
}

\begin{abstract}
Introduction: Only a few studies have concerned the timing of chest drains' removal in cardiac surgery patients following the coronary artery bypass graft (CABG). None of them pertained to the off-pump CABG (OPCAB) procedure.

Aim: To compare thoracic drainage time in OPCAB patients before the implementation of the institutional Enhanced Recovery After Surgery (ERAS) protocol and after that.

Material and methods: It was a single-center observational study concerning patients following OPCAB. Two groups of patients were analyzed: after implementing the ERAS protocol, the ERAS group, and before this period, the standard care group (STAND group). The primary outcome of this study was to compare postoperative drainage time in the ERAS and STAND groups. The other outcomes included comparing transfused blood products, postoperative complications, surgical technique, postoperative ventilation and the intensive care unit stay time.

Results: Sixty patients in the ERAS and 112 in the STAND group were analyzed. The postoperative drainage time was shorter in the ERAS than in the STAND group: 20 (17-22) vs. 30 (27-35) h, $p<0.001$. The number of transfused blood products was similar in both groups. No difference was noted between groups according to surgery and anesthesia time. However, patients in the ERAS group were ventilated for a significantly shorter time after the surgery and spent less time in the ICU than the STAND group. The number of postoperative complications in the ERAS and STAND group was 14 and 27, $p=1$.

Conclusions: The early removal of chest drains after OPCAB does not increase the risk of postoperative complications and demand for blood products. However, its impact on patients' morbidity needs further studies.
\end{abstract}

Key words: off-pump coronary artery bypass graft, Enhanced Recovery After Surgery, chest drainage.

\section{Introduction}

Coronary artery bypass graft (CABG) is the most commonly performed cardiac surgery procedure [1]. The offpump CABG (OPCAB) procedure, due to the lack of cardiopulmonary bypass, has some potential benefits, including reduction of systemic inflammation and decreased activation of platelets and coagulation [2]. Some studies showed better outcomes after OPCAB [3, 4]. However, this hypothesis was not confirmed in the large-scale, multicenter clinical trials $[1,5]$. Moreover, some data suggest a worse outcome in OPCAB patients [6]. These conflicting results may be caused by differences in surgical technique, perioperative period, and surgeon's experience [1].
Our previous experience in OPCAB patients showed that the implementation of the Enhanced Recovery After Surgery (ERAS) program in our institution, including a set of modifications in the perioperative period, reduced pain intensity and decreased intensive care unit (ICU) and hospital stay [7, 8]. However, some parameters, e.g. postoperative drainage impact on postoperative complications, were not analyzed in our studies.

\section{Aim}

This study aimed to compare thoracic drainage time in OPCAB patients before the implementation of the institutional ERAS protocol and after this period. The other goals

Address for correspondence: Slawomir Zurek, Clinical Department of Cardiac Surgery, District Hospital No. 2, Medical College, University of Rzeszow, Rzeszow, Poland, e-mail: s.zurek@ur.edu.pl Received: 26.01.2021, accepted: 6.03.2021. 
comprised comparing postoperative complications, transfused blood products, and ICU and hospital stay in both groups of patients.

\section{Material and methods}

This was a single-center observational study that occurred in a teaching hospital. The study protocol was reviewed and accepted by the Institutional Review Board of the Medical University of Lublin (permit number KE0254/219/2018).

\section{Patients}

The patients who were recruited after the implementation of the ERAS protocol signed the consent for the participation in the study (ERAS group). The ERAS group was compared with the historical cohort: participants operated on before initiating the ERAS program. Due to the retrospective nature of the standard care group (STAND group), patient consent was not obtained. Each patient was operated on by one of two surgeons.

\section{ERAS protocol}

The institutional ERAS protocol for OPCAB contained many elements, including preoperative consultation and information for the patient, patient and family education regarding the ERAS protocol (educational nurse); the lack of routine colon cleansing prior to the surgery; motivational spirometry; preoperative carbohydrate drink; perioperative anticoagulation prophylaxis; preoperative antibiotic prophylaxis; balanced fluid therapy; anesthesia with short-term drugs (remifentanil); the use of the erector spinae plane block; reduction of drainage time; multimodal analgesic therapy; the patient's extubation within several hours after the surgery; prevention of postoperative nausea and vomiting; oral diet on the first postoperative day; removal of the catheters and central cannula on the first postoperative day; and the discharge of the patient from the ICU on the first postoperative day.

Table I. Demographics

\begin{tabular}{lccc} 
Parameter & ERAS $(n=60)$ & STAND $(n=112)$ & $P$-value \\
Age [years] & $64.8(60.4-68.7)$ & $68.5(61.6-74.8)$ & 0.005 \\
\hline Female $(\%)$ & $8(13.3)$ & $18(16.1)$ & 0.82 \\
\hline Weight $[\mathrm{kg}]$ & $86.5(73.0-95.0)$ & $78.0(70.0-89.0)$ & 0.017 \\
\hline Height $[\mathrm{cm}]$ & $170.5(165.0-178.0)$ & $170.0(162.0-175.0)$ & 0.042 \\
\hline BMl & $28.9(26.9-30.3)$ & $28.1(25.4-30.7)$ & 0.29 \\
\hline ASA & $3(2-3)$ & $3(2-3)$ & 0.94 \\
\hline EF \% & $55(45-60)$ & $50(45-60)$ & 0.29 \\
\hline
\end{tabular}

ASA - American Society of Anesthesiologists scoring system, BMI - body mass index, EF - ejection fraction, ERAS - Enhanced Recovery After Surgery group, STAND - standard care group. The table presents patient demographics. The data are shown as medians and interquartile ranges for continuous variables or numbers and percentages for proportions. The probability was calculated with the Mann-Whitney $U$ test or the Fisher exact test.

\section{Outcomes}

The primary outcome of this study was to compare postoperative drainage time in the ERAS and STAND groups. The other outcomes included comparing transfused blood products, postoperative complications, surgical technique, postoperative ventilation and the ICU stay time.

\section{Statistical analysis}

Nonparametrically distributed data were calculated using the Mann-Whitney $U$ test and are presented as medians and interquartile ranges. Frequency variables and proportions were analyzed with the Fisher exact test. All measurements were performed using Statistica 13.1 software (Stat Soft. Inc., Tulsa, United States).

\section{Results}

The patients in the ERAS group were recruited from November 2018 to June 2020. The STAND group was analyzed from January 2016 to December 2017. Only patients operated on by two surgeons were enrolled in this study.

A significant difference was found for patients' age, weight, and height between both groups (Table I). Moreover, the preoperative urea and creatinine were significantly elevated in the STAND group (Table II). No difference was noted in preoperatively administered anticoagulation drugs (Table III).

\section{Primary outcome}

The drainage time was significantly shorter in the ERAS than the STAND group: 20 (17-22) vs. $30(27-35) h, p<0.001$ (Figure 1).

Table II. Preoperative laboratory tests

\begin{tabular}{lccc} 
Parameter & ERAS & STAND $(n=112)$ & $P$-value \\
Hemoglobin $[\mathrm{g} / \mathrm{dl}]$ & $13.2(12.8-14.4)$ & $13.4(12.5-14.3)$ & 0.8 \\
\hline Hematocrit $(\%)$ & $38.7(37.6-42.0)$ & $39.2(36.9-42.1)$ & 0.96 \\
\hline $\begin{array}{l}\text { WBC count } \\
\text { thousand/mm } 3 \text { ] }\end{array}$ & $7.5(6.4-8.5)$ & $7.4(6.1-8.6)$ & 0.80 \\
\hline $\begin{array}{l}\text { Platelet count } \\
\text { [thousand/mm } 3\end{array}$ & $243(200-270)$ & $222(187-259)$ & 0.09 \\
\hline Fibrinogen $[\mathrm{g} / \mathrm{l}]$ & $3.6(3.1-4.4)$ & $3.9(3.3-4.7)$ & 0.23 \\
\hline INR & $1.0(0.96-1.05)$ & $1.0(0.95-1.04)$ & 0.62 \\
\hline APTT $[\mathrm{s}]$ & $33.3(29.1-35.7)$ & $31.6(28.1-35.0)$ & 0.34 \\
\hline Creatinine $[\mathrm{mg} / \mathrm{dl}]$ & $1.04(0.88-1.22)$ & $0.91(0.81-1.11)$ & 0.01 \\
\hline Urea [mg/dl] & $39(32-50)$ & $37(28-46)$ & 0.04 \\
\hline $\begin{array}{l}\text { Blood glucose } \\
\text { level [mg/dl] }\end{array}$ & $110(97-124)$ & $108(96-133)$ & 0.85 \\
\hline Troponin [ng/l] & $12.1(8.3-42.7)$ & $15(10.0-44.6)$ & 0.28 \\
\hline
\end{tabular}

APTT - activated partial thromboplastin time, ERAS - Enhanced Recovery After Surgery group, INR - international normalized ratio, STAND - standard care group, WBC - white blood cells. The table presents the preoperative results of laboratory tests of patients in both groups. The data are shown as medians and interquartile ranges. The probability was calculated with the Mann-Whitney $\cup$ test. 
Table III. Preoperative treatment

\begin{tabular}{lccc} 
Treatment & ERAS & STAND & P-value \\
Eptifibatide (\%) & $4(6.7)$ & $15(13.4)$ & 0.21 \\
\hline Aspirin (\%) & $40(66.7)$ & $82(73.2)$ & 0.38 \\
\hline Clopidogrel (\%) & $1(1.7)$ & $5(4.5)$ & 0.43 \\
\hline Standard heparin (\%) & $2(3.3)$ & $14(12.5)$ & 0.06 \\
\hline LMWH & $46(76.7)$ & $87(77.7)$ & 1.0 \\
\hline
\end{tabular}

ERAS - Enhanced Recovery After Surgery group, LMWH - low-molecular-weight heparin, STAND - standard care group. The table presents the preoperative regime of anticoagulation drugs received by patients. The data are shown as numbers and percentages. The probability was calculated with the Fisher exact test.

\section{Secondary outcomes}

The number of transfused blood products was similar in both groups of patients and is presented in Table IV. No difference was noted between groups according to surgery and anesthesia time. However, a significant difference was recorded in the surgical technique. Arterial bypasses were more often performed in the ERAS group (Table IV). Moreover, patients in the ERAS group were ventilated for a significantly shorter time after the surgery and spent less time in the ICU than the STAND group (Table IV). No difference was found between the two groups in postoperative complications, including reoperation, cardiac tamponade, pleural puncture, dialysis, and local or systemic infection. The number of postoperative complications in the ERAS and STAND groups was 14 and 27, $p=1$. Only a single patient died in the postoperative period in the STAND group.

\section{Discussion}

The results of our study suggest that early removal of chest drains following OPCAB is safe and not associated with more postoperative complications or increased need to transfuse blood products. Moreover, patients in the ERAS group were ventilated for a shorter time and spent less time in the ICU.

In our previous study, a significant difference was found between the ERAS and the STAND group regarding the severity of postoperative pain and the consumption of opioids [7]. These differences in the ERAS group superiority were related to two factors: preoperative the erector spinae plane block and early removal of the chest drains.

To our knowledge, only a few studies have concerned the issue of timing of chest drain removal in cardiac surgery patients following the CABG. Each of these studies pertained to patients following on-pump CABG. In the trial by Mueller et al., shorter chest drainage (1 vs. 2 or 3 days) was associated with lower pain intensity [9]. No difference in adverse events was observed between the two groups in this study. Moreover, the author of the paper concluded that the early removal of chest drains simplified nursing care. Similar results to the previous research were reported by Mirmohammad-Sadeghi et al. [10]. The authors of this randomized controlled trial (RCT) also observed lower pain severity in patients whose chest drains were removed on

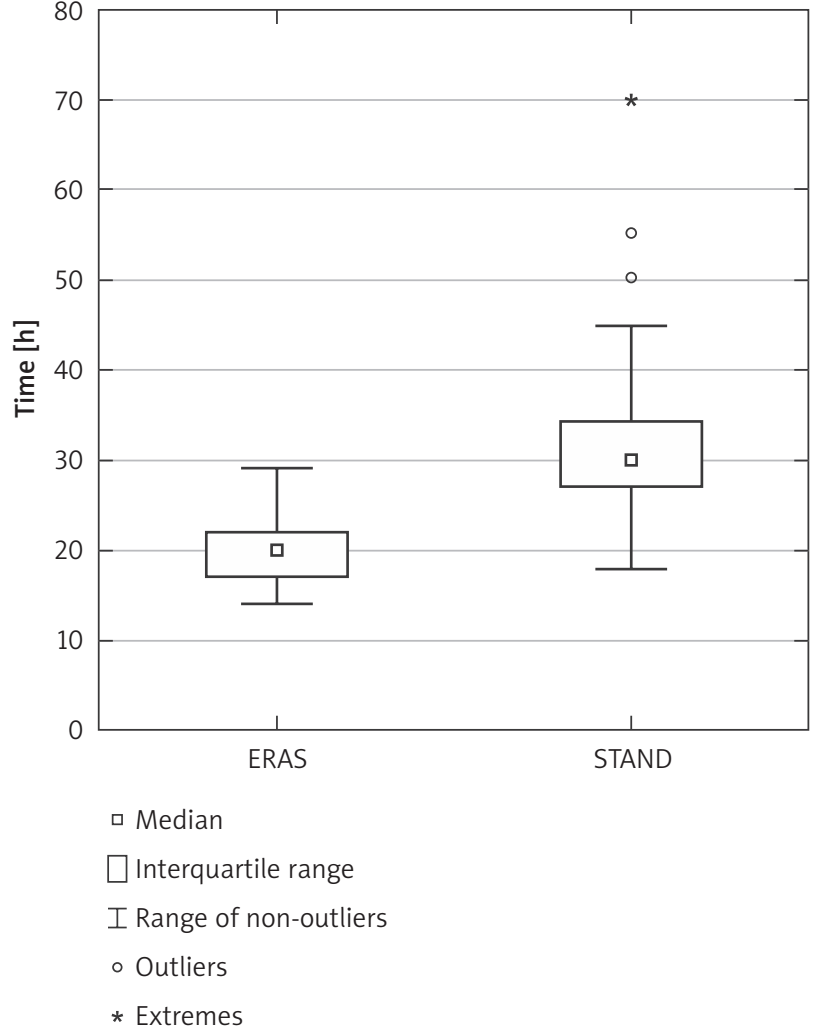

Figure 1. Time of postoperative drainage

Table IV. Perioperative period

\begin{tabular}{|c|c|c|c|}
\hline Variable & ERAS & STAND & $P$-value \\
\hline Surgery time [min] & $145(120-200)$ & 153 (130-195) & 0.40 \\
\hline Anesthesia time [min] & $190(150-240)$ & $195(170-238)$ & 0.40 \\
\hline $\begin{array}{l}\text { Postoperative } \\
\text { ventilation [h] }\end{array}$ & $4(2-5)$ & $10(7-13)$ & $<0.001$ \\
\hline $\begin{array}{l}\text { Postoperative ICU } \\
\text { stay [h] }\end{array}$ & $20(19-22)$ & $40(36-48)$ & $<0.001$ \\
\hline Number of bypasses & $3(2-3)$ & $3(2-3)$ & 0.48 \\
\hline LIMA + RIMA (\%) & $29(48.3)$ & $34(30.4)$ & 0.02 \\
\hline LRA (\%) & $4(6.7)$ & $16(14.3)$ & 0.21 \\
\hline $\begin{array}{l}\text { Packed red blood cells } \\
\text { in units }\end{array}$ & $0(0-2)$ & $0(0-2)$ & 0.16 \\
\hline Bags of platelets & $0(0-0)$ & $0(0-0)$ & 0.85 \\
\hline $\begin{array}{l}\text { Fresh frozen plasma } \\
\text { [units] }\end{array}$ & $0(0-0)$ & $0(0-2)$ & 0.27 \\
\hline
\end{tabular}

ERAS - Enhanced Recovery After Surgery group, ICU - intensive care unit, LIMA - left internal mammary artery, LRA - left radial artery, RIMA - right internal mammary artery, STAND - standard care group. The table presents surgery and anesthesia time, the number of bypasses, their type, and transfused blood products. The data are shown as medians and interquartile ranges for continuous variables or numbers and percentages for proportions. The probability was calculated with the Mann-Whitney $\mathrm{U}$ test or the Fisher exact test.

the first rather than on the second day after the CABG. Participants in the RCT by Abramov et al. were randomly assigned to two groups in which chest drains were removed after 24 or $48 \mathrm{~h}$ following the surgery [11]. Although the authors of this study measured many perioperative out- 
comes, a significant difference between groups was only found for early mobilization in the advantage of the group with shorter drainage.

Conversely to the previously mentioned studies, the results of retrospective analysis by Andreasen et al. showed a worse outcome in patients whose chest drains were removed earlier [12]. Pleural and pericardial effusion requiring invasive treatment was significantly more common when chest drains were removed around midnight on the day of surgery as apposed to the following morning. However, in comparison to the previously mentioned studies, chest drains were eliminated faster, which could affect the outcome.

Due to patients' retrospective enrollment in the STAND group in our study, this group was significantly older than the ERAS group. Patients' age influenced other variables, including height, weight, urea, creatinine, and the surgical technique in the current study. Arterial CABG is more often performed among younger individuals [13].

Our study has some limitations. It was an observational trial comparing a prospectively enrolled group with a historical cohort. Thus, demographic and laboratory differences were observed between groups. Pain intensity and analgesic use were not analyzed. Moreover, the volume of chest drains' discharge was not reported. Due to several modifications of the perioperative period between the ERAS and STAND groups, the effect of early removal of drains is elusive.

\section{Conclusions}

The early removal of chest drains after OPCAB does not increase the risk of postoperative complications and demand for blood products. However, its impact on patients' morbidity needs further studies.

\section{Disclosure}

The authors report no conflict of interest.

\section{References}

1. Lamy A, Devereaux PJ, Prabhakaran D, Taggart DP, Hu S, Straka Z, Piegas LS, Avezum A, Akar AR, Zanetti FL, Jain AR, Noiseux N, Padmanabhan C, Bahamondes JC, Novick RJ, Tao L, Olavegogeascoechea PA, Airan B, Sulling TA,
Whitlock RP, Ou Y, Gao P, Pettit S, Yusuf S, CORONARY Investigators Fiveyear outcomes after off-pump or on-pump coronary-artery by-pass grafting. N Engl J Med 2016; 375: 2359-68.

2. Gaudino M, Angelini GD, Antoniades C, Bakaeen F, Benedetto U, Calafiore AM, Di Franco A, Di Mauro M, Fremes SE, Girardi LN, Glineur D, Grau J, He GW, Patrono C, Puskas JD, Ruel M, Schwann TA, Tam DY, Tatoulis J, Tranbaugh R, Vallely M, Zenati MA, Mack M, Taggart DP; Arterial Grafting International Consortium (ATLANTIC) Alliance. Off-pump coronary artery bypass grafting: 30 years of debate. J Am Heart Assoc 2018; 7: e009934.

3. Kowalewski M, Pawliszak W, Malvindi PG, Bokszanski MP, Perlinski D, Raffa GM, Kowalkowska ME, Zaborowska K, Navarese EP, Kolodziejczak M, Kowalewski J, Tarelli G, Taggart DP, Anisimowicz L. Off-pump coronary artery bypass grafting improves short-term outcomes in high-risk patients compared with on-pump coronary artery bypass grafting: meta-analysis. J Thorac Cardiovasc Surg 2016; 151: 60-77.

4. Puskas JD, Thourani VH, Kilgo P, Cooper W, Vassiliades T, Vega JD, Morris C, Chen E, Schmotzer BJ, Guyton RA, Lattouf OM. Off-pump coronary artery bypass disproportionately benefits high-risk patients. Ann Thorac Surg 2009; 88: 1142-7.

5. Filardo G, Hamman BL, da Graca B, Sass DM, Machala NJ, Ismail S, Pollock BD, Collinsworth AW, Grayburn PA. Efficacy and effectiveness of on- versus off-pump coronary artery bypass grafting: a meta-analysis of mortality and survival. J Thorac Cardiovasc Surg 2018; 155: 172-9.e5.

6. Shroyer AL, Hattler B, Wagner TH, Collins JF, Baltz JH, Quin JA, Almassi GH, Kozora E, Bakaeen F, Cleveland Jr JC, Bishawi M, Grover FL; Veterans Affairs ROOBY-FS Group. Five-year outcomes after on-pump and off-pump coronaryartery bypass. N Engl J Med 2017; 377: 623-32.

7. Borys M, Żurek S, Kurowicki A, Horeczy B, Bielina B, Sejboth J, WołoszczukGębicka B, Czuczwar M, Widenka K. Implementation of Enhanced Recovery After Surgery (ERAS) protocol in off-pump coronary artery bypass graft surgery. A prospective cohort feasibility study. Anaesthesiol Intensive Ther 2020; 52: 10-4.

8. Kurowicki A, Borys M, Zurek S, Horeczy B, Gaweda B, Belina B, Trojnar B, Woloszczuk-Gebicka B, Sejboth J, Czuczwar M, Widenka K. Remifentanil and sevoflurane based anesthesia combined with bilateral erector spinae plane block in patients undergoing off-pump coronary artery bypass graft surgery. Videosurgery Miniinv 2020; 15: 346-50.

9. Mueller XM, Tinguely F, Tevaearai HT, Ravussin P, Stumpe F, von Segesser LK. Impact of duration of chest tube drainage on pain after cardiac surgery. Eur J Cardiothorac Surg 2000; 18: 570-4.

10. Mirmohammad-Sadeghi M, Etesampour A, Gharipour M, Shariat Z, Nilforoush P, Saeidi M, Mackie M, Sadeghi FM. Early chest tube removal after coronary artery bypass graft surgery. N Am J Med Sci 2009; 1: 333-7.

11. Abramov D, Yeshayahu M, Tsodikov V, Gatot I, Orman S, Gavriel A, Chorni I, Tuvbin D, Salis Tager, Apelbom A. Timing of chest tube removal after coronary artery bypass surgery. J Card Surg 2005; 20: 142-6.

12. Andreasen JJ, Sørensen GV, Abrahamsen ER, Hansen-Nord E, Bundgaard K, Bendtsen MD, Troelsen P. Early chest tube removal following cardiac surgery is associated with pleural and/or pericardial effusions requiring invasive treatment. Eur J Cardiothorac Surg 2016; 49: 288-292.

13. Itagaki S, Cavallaro P, Adams D, Chikwe J. Bilateral internal mammary artery grafts, mortality and morbidity: an analysis of 1526360 coronary bypass operations. Heart 2013; 99: 849-53. 